\title{
The association between protection motivation and hepatitis $b$ vaccination intention among migrant workers in Tianjin, China: a cross-sectional study
}

Cai Liu', Stephen Nicholas ${ }^{2,3,4,5}$ and Jian Wang ${ }^{6,7^{*}}$ (D)

\begin{abstract}
Background: Migrant workers are a susceptible population to the hepatitis b virus (HBV) and a vulnerable spot in China's immunization procedures. There is no free HBV immunization program for migrant workers in China, so understanding migrant workers' motivation to receive the HBV vaccine is the first step in designing effective immunization policies.
\end{abstract}

Methods: A fully specified protection motivation theory (PMT) model of HBV vaccination intention among migrant workers was specified. Data were collected through a cross-sectional survey of 406 migrant workers in three migrant-dense industries in Tianjin, China. Principal component factor analysis was used to produce PMT factors and nested binary logistic regression modeling was applied to assess the associations between protection motivation and HBV vaccination intention of migrant workers.

Results: The nested binary logistic regression model suggested that the severity factor and self-efficacy factor were positively related to HBV vaccination intention $(\mathrm{OR}=2.15,95 \% \mathrm{Cl}: 1.25-3.71 ; \mathrm{OR}=2.75,95 \% \mathrm{Cl}: 1.62-4.66)$ while the response costs was negatively related to the HBV vaccination motivation ( $\mathrm{OR}=0.50,95 \% \mathrm{Cl}$ : $0.29-0.83)$. The sociodemographic variables showed that younger, married and good self-rated health status participants were statistically associated with the intention of taking the HBV vaccine. Sex, education level and income group were not significantly associated with vaccination intention. The migrant-industry variables showed that migrant location had a strong effect on migrant workers' vaccination intention.

(Continued on next page)

\footnotetext{
* Correspondence: wangjian993@whu.edu.cn

${ }^{6}$ Dong Fureng Institute of Economic and Social Development, Wuhan

University, No.54 Dongsi Lishi Hutong, Dongcheng District, Beijing 100010,

China

7 Center for Health Economics and Management at School of Economics and

Management, Wuhan University, 299 Bayi Road, Wuchang District, Wuhan

430072, Hubei Province, China

Full list of author information is available at the end of the article
}

(c) The Author(s). 2020 Open Access This article is licensed under a Creative Commons Attribution 4.0 International License, which permits use, sharing, adaptation, distribution and reproduction in any medium or format, as long as you give appropriate credit to the original author(s) and the source, provide a link to the Creative Commons licence, and indicate if changes were made. The images or other third party material in this article are included in the article's Creative Commons licence, unless indicated otherwise in a credit line to the material. If material is not included in the article's Creative Commons licence and your intended use is not permitted by statutory regulation or exceeds the permitted use, you will need to obtain permission directly from the copyright holder. To view a copy of this licence, visit http://creativecommons.org/licenses/by/4.0/. The Creative Commons Public Domain Dedication waiver (http://creativecommons.org/publicdomain/zero/1.0/) applies to the data made available in this article, unless otherwise stated in a credit line to the data. 
(Continued from previous page)

Conclusion: Socio-demographic, migrant-industry variables and PMT factors (severity, self-efficacy and response costs) were statistically associated with migrant workers' intention to vaccinate. Our results suggest that health policy makers should provide more information to migrants on HBV severity; inform migrant workers on where, when and how to get the HBV vaccine; tap into work organizations as a location for vaccinations; and identify migrant worker subgroups for targeted interventions.

Keywords: Migrant workers, Hepatitis b vaccination, Vaccination intention, Protection motivation theory, Health education

\section{Background}

The hepatitis b virus (HBV) is ranked first among class $A$ and $B$ statutory reported infectious diseases in China, with 60-80,000 acute HBV cases reported each year [1]. While the routine immunization of children beginning in 1992 significantly reduced the horizontal transmission of $\mathrm{HBV}$, the vertical integration of $\mathrm{HBV}$ among adults poses a significant health challenge to China [2, 3]. Adults also accounted for most of China's 288 million migrant workers in 2018, making up more than one third of the entire working population [4]. With the HBV transmission route running through poor living conditions and high geographical mobility, migrant workers are a highly susceptible transmitter-recipient HBV population and a vulnerable spot in China's immunization procedures [5-7].

While the HBV vaccine can effectively prevent the spread of HBV among adults, migrant workers' lower vaccination prevalence than permanent workers is due to their poorer cognition of $\mathrm{HBV}$ and the $\mathrm{HBV}$ vaccine, lower education level and poorer health awareness levels, living in groups and lower accessibility to health care services [8-11]. While previous Chinese studies have identified an individual's knowledge and cognition of $\mathrm{HBV}$ and the $\mathrm{HBV}$ vaccine as key factors explaining $\mathrm{HBV}$ vaccination intentions and behavior, these studies only employed partial measures of HBV cognition [1214]. One exception was a study using protection motivation theory (PMT) to specify and test a cognition model of migrant workers' $\mathrm{HBV}$ vaccination intention, but the migrant-industry characteristics and key PMT factors, such as response costs, were excluded from the model [15]. Addressing these limitations, this paper applies a full PMT model, including migrant-industry variables and response costs, to explain migrant workers' $\mathrm{HBV}$ vaccination intention in the Binhai high migration region of Tianjin, and in three Tianjin industry sectors (manufacturing, retail and service), with a high proportion of migrant workers.

PMT is a widely used and powerful theoretical framework for assessing how individuals are motivated to react in a self-protective way towards a perceived health threat, which has informed public health issues in practice, especially implementing targeted health intervention strategies $[16,17]$. As set out in Fig. 1, individual cognition in the PMT model is divided into three parts: information source (derived from individual and environmental characteristics), threat appraisal (severity and vulnerability) and coping appraisal (response efficacy, self-efficacy and response costs) [18, 19]. Severity refers to the individual's subjective perception of the severity of a disease [19]. Vulnerability refers to an individual's cognition of the likelihood of getting sick, related to an individual's perception of the probability of being infected by HBV [20]. Response efficacy refers to the individual's perceived effectiveness of protective behavior in preventing and controlling the HBV threat [19]. Selfefficacy is the individual's ability to take protective action [19]. Response costs are the barriers to taking protective behaviour [19], mainly the price individuals would pay for protective behavior, measured by the cost of the $\mathrm{HBV}$ vaccine, but also the extent of $\mathrm{HBV}$ vaccination knowledge and worries about the side effects of the vaccine. Generally, the higher the individual's perception on severity, vulnerability, response efficacy and self-efficacy, the more likely protective behaviour is taken, while response costs hinder protective motivation or behavior.

We apply a full PMT model to answer the following questions: What was the intention of Tianjin migrant workers to receive the HBV vaccine?; How did Tianjin migrant workers assess the cost-benefit calculation of paying for the HBV vaccine?; and How can migrant workers' intentions to receive the $\mathrm{HBV}$ vaccine be improved? The answer to these questions can improve $\mathrm{HBV}$ vaccination policy in Tianjin and China.

\section{Methods}

Binahi New District in Tianjin provides a unique region for the study of migrant workers' HBV vaccination intention and for developing strategies to prevent and treat HBV for susceptible and high-risk migrant populations. Over the last decade, Tianjin's migrant population grew at $12-15 \%$ each year [21], with 5 million migrants accounting for $32 \%$ of Tianjin's population and about $60 \%$ of the Binhai New District population in 2017 [22]. Besides having a poorer cognition of $\mathrm{HBV}$ and the 


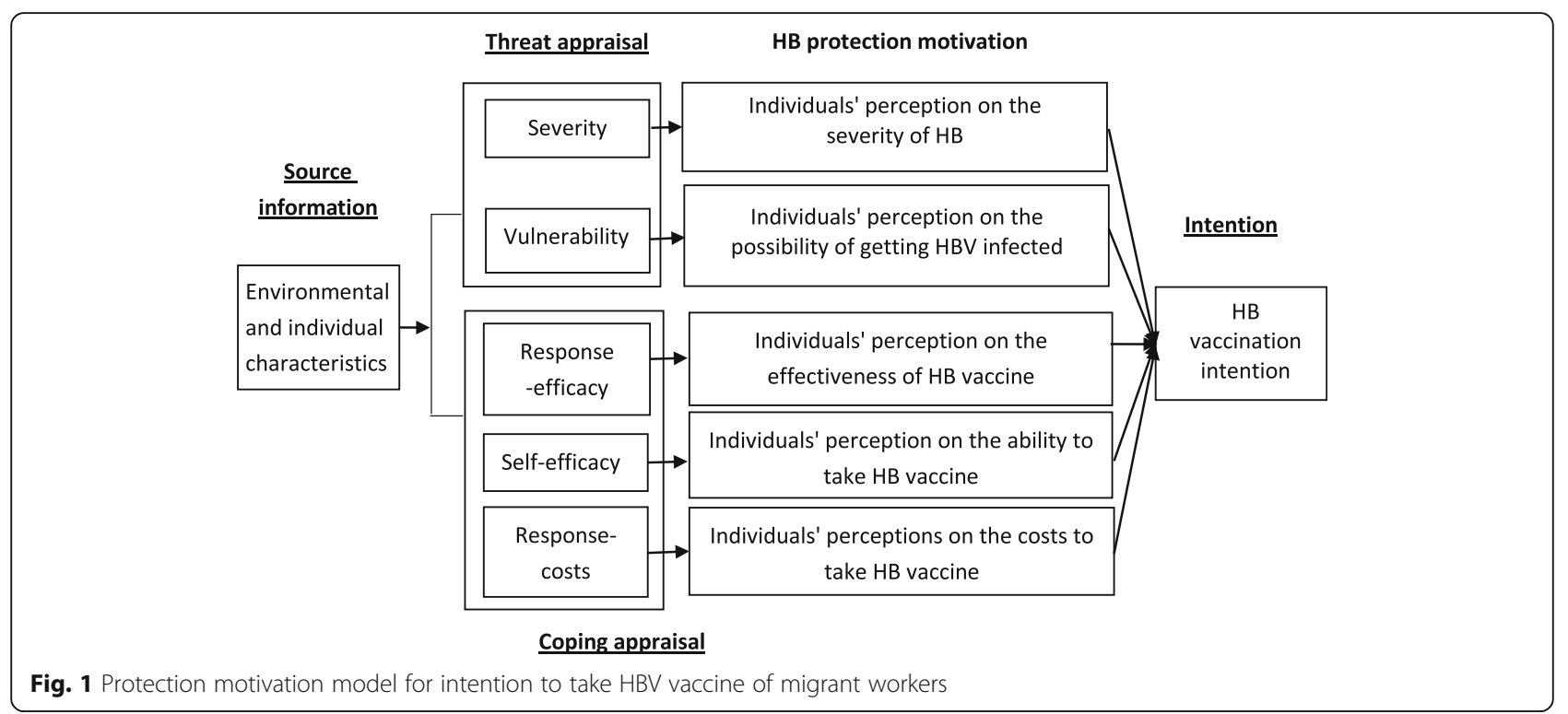

benefits of the HBV vaccine, Tianjin's migrant workers were excluded from the free 2018 vaccination program for local workers in close contact with HBV [23]. Migrant workers faced a cost-benefit calculation on whether to pay for the HBV vaccine or not. First, our full PMT model includes Tianjin migrant workers' response costs motivation to pay voluntarily for the HBV vaccine. Second, our model includes migrant-industry variables, specifically migrant location, whether migrants were accompanied or not by other family members and industry sector. Finally, our model includes health related behavior or intentions, mainly worker cognition, risk perceptions and likelihood to follow others in HBV vaccination intention.

\section{Study participants}

We surveyed migrant workers, who had lived for 6 months in the Binhai New District in Tianjin, but did not possess a Binhai New District household registration hukou. Given the high mobility and the lack of local registration of migrants, sampling "hidden populations", such as migrant workers, is difficult [24]. Employing the convenience sampling method, used, for example, in a previous study of migrant children's immunization in Beijing [25], we surveyed three migrant worker-dense industries between July and October in 2017: (1) manufacturing (including workers from food and electronic manufacturing companies); (2) retail (including workers in supermarket and electrical appliances selling markets); and (3) services (including taxi drivers, hotel and restaurant workers). Following previous studies on sample size selection [26, 27], we calculated that at least $385 \mathrm{mi}-$ grant workers should be surveyed based on the expected willingness to participate of $50 \%$ and a tolerance error of
0.1. Considering $10 \%$ dropped samples and balancing the sample size in each industry, questionnaires were administered to 150 workers in each industry who met the inclusion criteria of living at least 6 months in the Binhai New District in Tianjin, but did not possess a Binhai New District household registration hukou, and selfidentified as having no HBV vaccination history. After excluding unqualified and incomplete questionnaires, our sample consisted of 406 migrant workers, 133 from the retail, 119 from the manufacturing and 154 from the services industry, with a response rate of $90.2 \%$. We divided migrants into Tianjin migrants, with a non-Binhai New District hukou, but a Tianjin hukou, and nonTianjin migrants, with a non-Binhai New District and non-Tianjin hukou.

\section{Data collection}

A pilot survey was performed both to train postgraduate students from Tianjin University of Traditional Chinese Medicine to conduct the survey and to test the questionnaire for its comprehension. Supported by the Binhai local health authority, we contacted the principals in selected companies and factories to facilitate the survey and to ensure a high response rate. Data on participants' socio-demographic characteristics, migrant-industry characteristics, PMT measurement items and HBV vaccination intentions were obtained in face-to-face interviews, where all participants were volunteers and informed about their right not to answer questions. The intention to take the HBV vaccine was measured by a self-report question: "Will you take the HBV vaccine in the future?" with a binary yes or no response. The vaccination intention rate was $67.2 \%$. 


\section{PMT measurements}

Based on previous studies and migrant workers' characteristics, we designed items for each PMT construct using a 5-point Likert scale ranging from 1 (strongly disagree) to 5 (strongly agree). The severity of HBV was measured by the migrant workers' cognition on clinical symptoms, the costs for the individual and their family, and social discrimination. Vulnerability refers to the migrant's perceived infection probability compared with local workers. Similar to previous studies, response efficacy was measured by the migrant workers' perception on safety and effectiveness of HBV vaccine. Self-efficacy was measured by migrants' attitude to the advice of nearby people, the work organization, family, friends or doctors on vaccinations [28]. Response costs are the migrant workers' realized barriers facing the individual to adopt the protective behavior, measured by the vaccination information and worries about the side effects of the vaccine, and the price of protective behavior, measured by the cost of the HBV vaccine.

As set out in Table 1, factor analysis and Cronbach's alpha were employed to test the validity and reliability of the PMT measurement tool. As PMT assumes a close relationship between some of the constructs, an oblique rotation specially designed to maximize the correlation among factors was selected to extract the factors [20]. Using the minimum eigenvalue criterion of 1.0, Table 1 displays the PMT factors generated by producing a factor score on five dimensions, comprising severity, vulnerability, response efficacy, self-efficacy and response costs. Each respondent's PMT factor scores were dichotomized by the cutoff point of their mean value: high $(\min \leq$ factor score $\leq$ mean) and high $($ mean $<$ factor score $\leq \max )$.

\section{Covariates}

The covariates included socio-demographic and migrant-industry characteristics of the migrant workers. Socio-demographic characteristics consisted of age, sex, education level, marital status, self-rated health and income group. Education level was divided into three groups: low (below senior high school), medium (senior high school or equivalent) and high (above senior high school). Marital status included two categories: married and unmarried (including the divorced and widow). Selfrated health was measured by the respondents' selfassessment of their current health compared with those who were in the same age cohort and was divided into three groups: poor, medium and good. The income group variable was based on tertiles of the respondent's

Table 1 PMT assessment tool and factor analysis for migrant workers

\begin{tabular}{|c|c|c|c|}
\hline Factors and items & Loading & Variance & Cronbach's alpha \\
\hline \multicolumn{4}{|l|}{ F1-Severity factor } \\
\hline HBV is incurable. & 0.56 & 4.16 & 0.88 \\
\hline It is expensive to cure HBV. & 0.66 & & \\
\hline The symptom of HBV is unbearable. & 0.83 & & \\
\hline HBV would bring huge mental stress for the family. & 0.84 & & \\
\hline HBV patients and HBV carrier would suffer from social discrimination. & 0.70 & & \\
\hline \multicolumn{4}{|l|}{ F2-Self efficacy factor } \\
\hline I would like to take HBV vaccine if people around me mostly choose to. & 0.83 & 2.82 & 0.87 \\
\hline I would like to take HBV vaccine if it is organized by the workplace. & 0.85 & & \\
\hline I would like to take HBV vaccine if the family and friends recommend that. & 0.78 & & \\
\hline I would like to take HBV vaccine if the doctor advice that. & 0.63 & & \\
\hline \multicolumn{4}{|l|}{ F3-Response efficacy factor } \\
\hline HBV vaccine is developed enough for common use. & 0.73 & 1.85 & 0.84 \\
\hline Taking vaccine is an effective way to prevent HBV. & 0.75 & & \\
\hline \multicolumn{4}{|l|}{ F4-Vulnerability factor } \\
\hline As the migrant, the risk to get HBV infected is higher than other population. & 0.61 & 1.24 & 0.81 \\
\hline People around me getting HBV infected are more than before. & 0.63 & & \\
\hline \multicolumn{4}{|l|}{ F5-Response costs factor } \\
\hline It is inconvenient for me to take HBV vaccine. & 0.56 & 1.14 & 0.61 \\
\hline I do not have enough information to take HBV vaccine. & 0.48 & & \\
\hline The side effect is serious when taking HBV vaccine. & 0.65 & & \\
\hline Cumulative(\%) & 87.13 & & \\
\hline
\end{tabular}


Table 2 Characteristics of migrant workers in Tianjin and bivariate analysis of the variables

\begin{tabular}{|c|c|c|c|c|}
\hline Characteristics & $N(\%)$ & OR & $95 \% \mathrm{Cl}$ & $P$ \\
\hline Observations & $406(100)$ & & & \\
\hline \multicolumn{5}{|l|}{ Age (years) } \\
\hline $16-35$ & $168(41.4)$ & 1.0 & & \\
\hline $35-45$ & 99 (24.4) & 0.74 & $0.43-1.28$ & 0.284 \\
\hline $45-65$ & $139(34.2)$ & 0.51 & $0.32-0.83$ & 0.006 \\
\hline \multicolumn{5}{|l|}{ Gender } \\
\hline male & $210(51.7)$ & 1.0 & & \\
\hline Female & $196(48.3)$ & 0.99 & $0.65-1.50$ & 0.965 \\
\hline \multicolumn{5}{|l|}{ Education level } \\
\hline Low & 79 (19.5) & 1.0 & & \\
\hline Medium & $109(26.8)$ & 1.49 & $0.81-2.73$ & 0.201 \\
\hline High & $218(53.7)$ & 1.39 & $0.82-2.38$ & 0.222 \\
\hline \multicolumn{5}{|l|}{ Marital status } \\
\hline Married & $312(76.8)$ & 1.0 & & \\
\hline Unmarried & $94(23.2)$ & 1.05 & $0.64-1.72$ & 0.842 \\
\hline \multicolumn{5}{|l|}{ Self-rated health } \\
\hline Poor & $101(24.9)$ & 1.0 & & \\
\hline Medium & $163(40.1)$ & 0.93 & $0.55-1.55$ & 0.771 \\
\hline Good & $142(35.0)$ & 1.63 & $0.94-2.84$ & 0.085 \\
\hline \multicolumn{5}{|l|}{ Income group } \\
\hline Low & $133(32.8)$ & 1.0 & & \\
\hline Medium & 96 (23.6) & 0.93 & $0.54-1.60$ & 0.793 \\
\hline High & 177 (43.6) & 1.61 & $0.99-2.62$ & 0.053 \\
\hline \multicolumn{5}{|l|}{ Migrant location } \\
\hline Non-Tianjin migrants & $49(12.1)$ & 1.0 & & \\
\hline Tianjin migrants & $357(87.9)$ & 1.12 & $0.59-2.14$ & 0.733 \\
\hline \multicolumn{5}{|l|}{ Migrant accompanied } \\
\hline Yes & $301(74.1)$ & 1.0 & & \\
\hline No & $105(25.9)$ & 0.91 & $0.57-1.46$ & 0.699 \\
\hline \multicolumn{5}{|l|}{ Industry } \\
\hline Manufacturing & $133(32.8)$ & 1.0 & & \\
\hline Retail & $119(29.3)$ & 1.54 & $0.91-2.61$ & 0.107 \\
\hline Services & $154(37.9)$ & 1.51 & $0.92-2.46$ & 0.101 \\
\hline \multicolumn{5}{|l|}{ Severity } \\
\hline Low & $193(53.0)$ & 1.0 & & \\
\hline High & $171(47.0)$ & 1.98 & $1.26-3.10$ & 0.003 \\
\hline \multicolumn{5}{|l|}{ Vulnerability } \\
\hline Low & $156(42.9)$ & 1.0 & & \\
\hline High & $208(57.1)$ & 0.98 & $0.63-1.52$ & 0.923 \\
\hline \multicolumn{5}{|l|}{ Response efficacy } \\
\hline Low & $198(54.4)$ & 1.0 & & \\
\hline High & $166(45.6)$ & 0.85 & $0.55-1.32$ & 0.464 \\
\hline
\end{tabular}

Self-efficacy 
Table 2 Characteristics of migrant workers in Tianjin and bivariate analysis of the variables (Continued)

\begin{tabular}{lllll}
\hline Characteristics & $\mathrm{N}(\%)$ & $\mathrm{OR}$ & $95 \% \mathrm{Cl}$ & $\mathbf{1 . 6 8 - 4 . 2 0}$ \\
\hline High & $176(48.3)$ & 2.66 & \\
Response costs & & & $\mathbf{0 . 0 0 0}$ \\
Low & $143(39.3)$ & 1.0 & $0.34-0.87$ \\
High & $221(60.7)$ & 0.55 & $\mathbf{0 . 0 1 1}$ \\
\hline
\end{tabular}

Odds ratios $95 \% \mathrm{Cl}$ and $p$ value are shown

average monthly income. Migrant-industry characteristics included migrant location (non-Tianjin migrant or Tianjin migrant); whether the migrant was accompanied by family or not; and industry groups (manufacturing, retail and services).

\section{Data analysis}

We estimated the frequency of migrant workers' intention to obtain the HBV vaccination. Severity factor, vulnerability factor, response efficacy factor, self-efficacy factor and response costs factor were produced by principal component factor analysis. Bivariate analysis of PMT factors and covariates with the dependent variable were conducted by logistic regression modeling. As set out in Models 1-3 below, socio-demographic characteristics variables, migrant-industry variables and PMT factors were added into the binary logistic regression model, where the dependent variable was the intention to $\mathrm{HBV}$ vaccinate.

$$
{ }_{\varepsilon^{1}} \text { Model 1: } f^{1}(P)=\alpha^{1}+\beta^{1}{ }_{1} X_{\text {Socio-demographic characteristics }}+
$$

Model 2: $f^{2}(P)=\alpha^{2}+\beta^{2}{ }_{1} X_{\text {Socio-demographic characteristics }}+$ $\beta_{2}^{2} X_{\text {Migrant-industry characteristics }}+\varepsilon^{2}$

Model 3: $f^{3}(P)=\alpha^{3}+\beta^{3}{ }_{1} X_{\text {Socio-demographic characteristics }}+$ $\beta_{2}^{3}{ }_{2}$ Migrant-industry characteristics $+\beta^{3}{ }_{3} X_{\text {PMT factors }}+\varepsilon^{3}$

All statistical analysis was performed using STATA 15.1 with two-tailed tests and $p<0.05$ was taken as the statistically significant level. Given the nested characteristics of the models, the likelihood ratio test was employed to show the goodness of fitness of the model.

\section{Results}

Table 2 present the characteristics of the 406 respondents. The sex of the respondents was roughly equal (male 51.7\%); $58.6 \%$ were over 35 years old; $53.7 \%$ had an education level of above senior high school; and $74.1 \%$ were accompanied by family. In our sample, 273 $(67.2 \%)$ intended to take the vaccine in the future, while 133 respondents $(32.8 \%)$ had no intention to vaccinate. For the PMT scores, the low severity (53.0\%), response efficacy (54.4\%) and self-efficacy (51.7\%) groups were slightly larger than the high groups, while the response costs $(60.7 \%)$ and vulnerability $(57.1 \%)$ groups were larger than the low groups. HBV vaccination intentions differed by age $(p=0.006)$, self-rated health $(p=0.085)$, income $(p=0.053)$, severity $(p=0.003)$, self-efficacy $(p=0.000)$ and response costs $(p=0.011)$.

In the measurement of PMT, two items ("The number of HBV patients and carriers are larger than before" and "The price of HBV vaccine is very expensive"), whose contribution rate was less than 0.45 , were screened out in the factor analysis [29]. Using the minimum eigenvalue criterion of 1.0, factor analysis yielded five conceptually distinct factors that explained $87.13 \%$ of the total variance in measuring PMT. As shown in Table 1, the overall Cronbach's alpha coefficient for PMT was 0.84, with the Cronbach's alpha coefficient 0.88 for severity; 0.87 for vulnerability; 0.84 for response efficacy; 0.81 for self-efficacy; and 0.61 for response costs.

The results of logistic regression are shown in Table 3. In Model 3, severity (OR $=2.15,95 \% \mathrm{CI}: 1.25-3.71)$ and self-efficacy $(\mathrm{OR}=2.75,95 \% \mathrm{CI}: 1.62-4.66)$ were positively and significantly related to vaccination intention and the response costs (OR $=0.50,95 \%$ CI:0.29-0.83) was negatively and significantly related to motivation to take the vaccine. The likelihood ratio (LR) test in Table 3 shows that the PMT constructs improved the goodness of fitness of the model (LR chi2 $(5)=33.27$ and $p<$ $0.05)$. As for the migrant-industry variables, Tianjin migrant workers were more likely to choose the vaccine in the future than non-Tianjin migrants $(\mathrm{OR}=3.310,95 \%$ CI:1.37-7.99), while migrants accompanied by family and industry type had no influence on vaccination intentions. Younger, married and good self-rated health status participants were statistically associated with the intention of taking the HBV vaccine.

\section{Discussion}

Based on PMT, our study investigated the association between protection motivation and HBV vaccination intention among migrant workers in Tianjin, China. To our knowledge, this is the first attempt to integrate all PMT constructs into a HBV vaccination intention study for a migrant population. We found that a significant percentage of the migrant workers, 133 of the respondents or $32.8 \%$ of the sample, lacked the intention to vaccinate and that $\mathrm{HBV}$ protection motivation strongly affected migrant workers' HBV vaccination intention. Given that migrant workers are a susceptible population to HBV and a vulnerable spot in China's immunization 
Table 3 Nested logistic regression model of determinants of HB vaccinate intention among migrant workers in Tianjin

\begin{tabular}{|c|c|c|c|c|c|c|c|c|c|}
\hline \multirow[t]{2}{*}{ Variables } & \multicolumn{3}{|c|}{ Model 1} & \multicolumn{3}{|c|}{ Model 2} & \multicolumn{3}{|c|}{ Model 3} \\
\hline & $\overline{\mathrm{OR}}$ & $95 \% \mathrm{Cl}$ & $P$ & $\overline{\mathrm{OR}}$ & $95 \% \mathrm{Cl}$ & $P$ & $\overline{\mathrm{OR}}$ & $95 \% \mathrm{Cl}$ & $P$ \\
\hline \multicolumn{10}{|l|}{ Gender } \\
\hline Male & 1.0 & & & 1.0 & & & 1.0 & & \\
\hline Female & 0.84 & $0.53-1.34$ & 0.463 & 0.80 & $0.49-1.28$ & 0.345 & 0.71 & $0.43-1.18$ & 0.191 \\
\hline \multicolumn{10}{|l|}{ Age } \\
\hline $16-35$ & 1.0 & & & 1.0 & & & 1.0 & & \\
\hline $35-45$ & 0.44 & $0.21-0.90$ & 0.025 & 0.38 & $0.18-0.80$ & 0.011 & 0.28 & $0.12-0.63$ & 0.002 \\
\hline $45-65$ & 0.36 & $0.18-0.72$ & 0.004 & 0.33 & $0.16-0.68$ & 0.003 & 0.35 & $0.16-0.77$ & 0.009 \\
\hline \multicolumn{10}{|l|}{ Education level } \\
\hline low & 1.0 & & & 1.0 & & & 1.0 & & \\
\hline Medium & 0.73 & $0.34-1.59$ & 0.428 & 0.65 & $0.27-1.56$ & 0.330 & 0.56 & $0.22-1.42$ & 0.225 \\
\hline High & 1.21 & $0.66-2.23$ & 0.536 & 1.26 & $0.65-2.43$ & 0.492 & 1.23 & $0.62-2.48$ & 0.554 \\
\hline Marital status & 1.81 & $0.93-3.54$ & 0.080 & 2.29 & $1.10-4.80$ & 0.028 & 3.17 & $1.44-6.98$ & 0.004 \\
\hline \multicolumn{10}{|l|}{ Self-rated health } \\
\hline Poor & 1.0 & & & 1.0 & & & 1.0 & & \\
\hline Medium & 1.01 & $0.57-1.79$ & 0.962 & 1.20 & $0.66-2.19$ & 0.553 & 1.78 & $0.91-3.46$ & 0.090 \\
\hline Good & 1.88 & $1.00-3.54$ & 0.052 & 2.17 & $1.10-4.25$ & 0.025 & 3.37 & $1.61-7.09$ & 0.001 \\
\hline \multicolumn{10}{|l|}{ Income group } \\
\hline Low & 1.0 & & & 1.0 & & & 1.0 & & \\
\hline Medium & 0.63 & $0.35-1.14$ & 0.129 & 0.60 & $0.33-1.12$ & 0.107 & 0.65 & $0.34-1.24$ & 0.191 \\
\hline High & 1.21 & $0.70-2.10$ & 0.497 & 1.41 & $0.80-2.48$ & 0.236 & 1.26 & $0.68-2.34$ & 0.466 \\
\hline \multicolumn{10}{|l|}{ Migrant location } \\
\hline Tianjin migrant & & & & 1.0 & & & 1.0 & & \\
\hline Non-tianjin migrant & & & & 2.55 & $1.15-5.65$ & 0.021 & 3.31 & $1.37-7.99$ & 0.008 \\
\hline \multicolumn{10}{|l|}{ Migrant accompanied } \\
\hline Yes & & & & 1.37 & $0.79-2.38$ & 0.264 & 1.27 & $0.71-2.28$ & 0.428 \\
\hline No & & & & 1.0 & & & 1.0 & & \\
\hline \multicolumn{10}{|l|}{ Industry } \\
\hline Manufacturing & & & & 0.61 & $0.32-1.17$ & 0.137 & 0.68 & $0.34-1.38$ & 0.287 \\
\hline Retail & & & & 1.0 & & & 1.0 & & \\
\hline Service & & & & 1.11 & $0.56-2.19$ & 0.760 & 1.26 & $0.62-2.58$ & 0.521 \\
\hline \multicolumn{10}{|l|}{ Severity } \\
\hline Low & & & & & & & 1.0 & & \\
\hline High & & & & & & & 2.15 & $1.25-3.71$ & 0.006 \\
\hline \multicolumn{10}{|l|}{ Vulnerability } \\
\hline Low & & & & & & & 1.0 & & \\
\hline High & & & & & & & 1.07 & $0.64-1.78$ & 0.809 \\
\hline \multicolumn{10}{|l|}{ Response efficacy } \\
\hline Low & & & & & & & 1.0 & & \\
\hline High & & & & & & & 0.86 & $0.50-1.46$ & 0.565 \\
\hline \multicolumn{10}{|l|}{ Self-efficacy } \\
\hline Low & & & & & & & 1.0 & & \\
\hline High & & & & & & & 2.75 & $1.62-4.66$ & 0.000 \\
\hline
\end{tabular}

Response costs 
Table 3 Nested logistic regression model of determinants of HB vaccinate intention among migrant workers in Tianjin (Continued)

\begin{tabular}{|c|c|c|c|c|c|c|c|c|c|}
\hline \multirow[t]{2}{*}{ Variables } & \multicolumn{3}{|c|}{ Model 1} & \multicolumn{3}{|c|}{ Model 2} & \multicolumn{3}{|c|}{ Model 3} \\
\hline & $\mathrm{OR}$ & $95 \% \mathrm{Cl}$ & $P$ & $\mathrm{OR}$ & $95 \% \mathrm{Cl}$ & $P$ & OR & $95 \% \mathrm{Cl}$ & $P$ \\
\hline Low & & & & & & & 1.0 & & \\
\hline High & & & & & & & 0.50 & $0.29-0.83$ & 0.008 \\
\hline Pseudo R2 & 0.050 & & & 0.074 & & & 0.146 & & \\
\hline$P$ & 0.011 & & & 0.002 & & & 0.000 & & \\
\hline$-2 L L$ & 438.56 & & & 427.48 & & & 394.21 & & \\
\hline
\end{tabular}

Odds ratios $95 \% \mathrm{Cl}$ and $p$ value are shown

procedures, our study recommends specific health education designs and immunization management polices as key interventions for addressing HBV transmission.

As several PMT meta-analyses $[16,17]$ argued, the specificity of the PMT measurement for special populations are crucial, especially when PMT-based research is used to guide health policy at an operational level. Validating our PMT approach, Model 3 shows that severity, self-efficacy and response costs were significant constructs determining migrant workers' HBV vaccination intention. While our results share similarities with other PMT studies, a meta-analysis of PMT literature found that not all PMT variables are able to predict a given behavior or intention with the same strength. The role and influence of the PMT variables vary across different vaccination domains and research populations $[16,17]$. For example, compared to severity and vulnerability, response efficacy, self-efficacy and response costs usually have stronger relationships with the adaptive intention to vaccinate [16]. One of the most researched areas, influenza vaccination intention studies, found that response efficacy and self-efficacy tended to be significant vaccination predictors [30, 31]. In Liu et al's [15] partial PMT model, vulnerability and response efficacy were found to be the most significant PMT constructs determining migrants' HBV vaccination intention. These different results reflect different study places, different measurement tools and different model specifications. Importantly, our fully specified PMT model included response costs data, information on the migration location, and whether the migrant was accompanied by family members and industry covariates.

The effect of severity in our PMT model of vaccination intention suggests that the content of HBV education messages should emphasize the severity of HBV, including identifying symptoms, the heavy economic burden, the worries and pain on family members, the barriers to acquiring employment and potential social discrimination. Self-efficacy as a strong predictor of migrant workers' vaccination intention informs health authorities to tap into work organizations as a location for vaccinations where other workers being vaccinated encourages individuals to vaccinate. According to the response costs content, barriers to migrant workers' vaccinations should be addressed directly by health education content and vaccination management policy, including side effects of the vaccine. Health authorities should provide more information on where, when and how to get the HBV vaccine and establish more vaccination sites, especially in migrant workers' workplaces or by providing visiting injection services.

For the socio-demographic and migrant-industry variables, marital status, self-rated health and migrant location were the key determinants to the migrant workers' vaccination intention, which suggests that HBV prevention and education policy should focus on the migrant workers who are in the older, unmarried and in poor self-rated health status groups and HBV health education and vaccination management policy should concentrate on migrant workers from other provinces. We expected industry differences since migrant workers in the retail and service industry were required by the government to undergo a physical examination before starting work. This absence of industry differences might reflect a high level of inadequate $\mathrm{HBV}$ and $\mathrm{HBV}$ vaccine knowledge by migrant workers irrespective of industry sector. If migrant workers were ill-informed about HBV, then health officials are missing an opportunity to educate migrant workers in services and retail industries on the benefits of the HBV vaccine during the physical examination process. One place to improve migrant worker HBV education is during the existing testing of workers. We also recommend an expansion of the testing regime to all workplaces.

\section{Study limitations}

Maladaptive response rewards were not included in our PMT model. In some previous vaccination studies, maladaptive response rewards were measured by saving money or time, avoiding the side effects of the vaccine and acquiring natural immunity to subsequent infection [31, 32]. Since HBV is incurable, acquiring natural immunity does not exist, and saving expenses and worries about the side effects have been included in response costs, so maladaptive response rewards may not be a serious omission in our PMT model. However, maladaptive 
response rewards warrants empirical study in future HBV research. Second, our study did not assess vaccination behaviour directly. While it has been shown that vaccination behavior in empirical studies can be predicted by previous intention in a wide range of contexts $[33,34]$, future studies should include vaccination behavior directly. Third, as a result of convenience sampling, our results and findings need confirmation through studies of other migrant worker populations, regions and industries. Finally, data on Tianjin's migrant workers was collected through a convenience sample, which may limit the external generalisation of our results.

\section{Conclusion}

Our results showed that severity, self-efficacy and response costs from PMT were statistically associated with migrant workers' intention to vaccinate in Tianjin, China. The significance of these three PMT constructs inform health policy makers on how to improve health education and immunization policy for migrant workers' HBV vaccination intentions. We recommend policy makers provide more information to migrants on HBV severity; inform migrant workers on where, when and how to get the HBV vaccine; tap into work organizations as a location for vaccination; and identify migrant worker subgroups for targeted interventions.

\section{Abbreviations}

HB: Hepatitis B; HBV: Hepatitis B Virus; PMT: Protection Motivation Theory

\section{Acknowledgments}

The authors also thank Xiaofang Wang, Ying Li, Wenjing Lu, Yang Qin, and Zongpu Yue for their invaluable effort and support in the survey that made this study possible. The authors also acknowledge the helpful comments by the Editor and two reviewers.

\section{Authors' contributions}

$\mathrm{CL}$ and JW conceived of the research question and designed the study. $\mathrm{CL}$ did the statistical analyses, interpreted the results and drafted the article. SN revised the article critically providing important intellectual content. JW did the final approval of the version to be submitted. All authors read and approved the final manuscript.

\section{Funding}

The research was supported by the National Natural Science Foundation of China (grant number 71303171, 71702131). The first grant provided funding for the investigation and the second grant supported the interpretation of the data.

\section{Availability of data and materials}

The datasets used and analysed during the current study are available from the corresponding author on reasonable request.

\section{Ethics approval and consent to participate}

The study protocol was approved by The Ethical Committee of Tianjin University of Traditional Chinese Medicine, including collecting personal information. Written informed consent was required before the interviews, and participants were informed that they could refuse to answer any question. The questionnaire did not ask about infection status, and no biological samples were collected.
Consent for publication

Not Applicable.

\section{Competing interests}

The authors declare that they have no competing interests.

\section{Author details}

${ }^{1}$ School of Management, Tianjin University of Traditional Chinese Medicine, Tianjin 301617, China. ${ }^{2}$ Australian National Institute of Management and Commerce, 1 Central Avenue Australian Technology Park, Eveleigh Sydney, NSW 2015, Australia. ${ }^{3}$ Research Institute for International Strategies, Guangdong University of Foreign Studies, Baiyun Avenue North, Guangzhou 510420, People's Republic of China. ${ }^{4}$ School of Economics and School of Management, Tianjin Normal University, West Bin Shui Avenue, Tianjin 300074, China. ${ }^{5}$ Newcastle Business School, University of Newcastle, University Drive, Newcastle, NSW 2308, Australia. ${ }^{6}$ Dong Fureng Institute of Economic and Social Development, Wuhan University, No.54 Dongsi Lishi Hutong, Dongcheng District, Beijing 100010, China. ${ }^{7}$ Center for Health Economics and Management at School of Economics and Management, Wuhan University, 299 Bayi Road, Wuchang District, Wuhan 430072, Hubei Province, China.

Received: 25 April 2020 Accepted: 23 July 2020

Published online: 10 August 2020

\section{References}

1. CSY. China statistical yearbook, vol. 2018. Beijing: China Statistical Publishing House; 2019.

2. Zheng H, Wang FZ, Zhang GM, Cui FQ, Wu ZH, Miao N, et al. An economic analysis of adult hepatitis B vaccination in China. Vaccine. 2015;33(48):68319.

3. Liang XF, Bi SL, Yang WZ, Wang LD, Cui G, Cui FQ, et al. Epidemiological serosurvey of hepatitis B in China--declining HBV prevalence due to hepatitis B vaccination. Vaccine. 2009;27(47):6550-7.

4. National bureau of statistics. Statistical bulletin on national economic and social development 2018. http://www.stats.gov.cn/tjsj/zxfb/201902/t2019022 8_1651265.html. Accessed 28 Feb 2019

5. Teng XM. Prevalence and counter measures of infectious diseases among China's floating population. Occup Health. 2010;26(06):687-9.

6. Jiang XM, Zhou R, Han DL. Investigation on the prevalence of infectious diseases among migrant population in Chengdu in 2013. J Trop Dis Parasitol. 2015;13(4):219-22 in Chinese.

7. Liu F, Ge S, Ma R, Zhang J, Sun MP, Jia B, et al. Study on influencing factors of expanded program on immunization service among the floating children. Mod Prev Med. 2008;35(9):1716-8.

8. Li J, Yao J, Shan H, Chen Y, Jiang ZG, Ren JJ, et al. Comparison of the effect of two different doses of recombinant hepatitis $B$ vaccine on immunogenicity in healthy adults. Hum Vaccin Immunother. 2015;11(5): 1108-13.

9. Chen R, Li Y, Wangen KR, Nicholas S, Maitland E, Wang J. Hepatitis B birth dose vaccination rates among children in Beijing: a comparison of local residents and first and second generation migrants. Hum Vaccin Immunother. 2016;12(5):1141-8.

10. Vedio A, Liu EZ, Lee ACK, Salway S. Improving access to health care for chronic hepatitis B among migrant Chinese populations: a systematic mixed methods review of barriers and enablers. J Viral Hepat. 2017;24(7):526-40.

11. Xiang H, Tang XJ, Xiao M, Gan L, Chu K, Li SH, et al. Study on status and willingness towards hepatitis $B$ vaccination among migrant workers in Chongqing,China: A cross-sectional study. Int J Environ Res Public Health. 2019;16(20):4046.

12. Zhu DW, Wang J, Wangen KR. Hepatitis B vaccination coverage rates among adults in rural China: are economic barriers relevant? Vaccine. 2014; 32(49):6705-10

13. Hou ZY, Chang J, Yue DH, Fang H, Meng QY, Zhang Y. Determinants of willingness to pay for self-paid vaccines in China. Vaccine. 2014;32(35):44717.

14. Abioduna O, Shobowaleb O, Elikwub C, Ogbaroc D, Omotoshod A, Markd B, et al. Riskperception and knowledge of hepatitis B infection among cleaners in a tertiary hospital in Nigeria: a cross-sectional study. Clin Epidemiol Glob Health. 2019;7(1):11-6. 
15. Liu RG, Li YW, Wangen KR, Maitland E, Nicholas S, Wang J. Analysis of hepatitis $B$ vaccination behavior and vaccination willingness among migrant workers from rural China based on protection motivation theory. Hum Vaccin Immunother. 2016;12(5):1155-63.

16. Floyd DL, Prentice-Dunn S, Ronald RW. A meta-analysis of research on protection motivation theory. J Appl Soc Psychol. 2000;30(2):407-29.

17. Milne $S$, Sheeran $P$, Orbell S. Prediction and intervention in health-related behavior: a meta-analytic review of protection motivation theory. J Appl Soc Psychol. 2006;30(1):106-43.

18. Ronald RW. A protection motivation theory of fear appeals and attitude change. J Psychol Interdis Appl. 1975;91(5):93-114.

19. Ronald RW, Cacioppo JT, Petty R. Cognitive and physiological processes in fear appeals and attitude change: a revised theory of protection motivation. New York: Social Psychophysiology: A Sourcebook; 1983.

20. Tabachnick BG, Fidell LS. Principle components and factor analysis. In: Rothman JL, MacElree E, editors. Using multivariate statistics. New York: Harper Collins; 1999. p. 597-667.

21. Xu Y, Fu YY, Wan Y. Investigation on health education of tuberculosis among migrant population in Tianjin Binhai new area. Chinese J Health Educ. 2014;30(4):344-6.

22. Tianjin Statistics Bureau. 2018 Tianjin statistical bulletin on national economic and social development. http://stats.tj.gov.cn/Category_1/Index. aspx. Accessed 1 March 2019

23. Tianjin Municipal People's Government. The municipal finance department arranged funds to provide hepatitis $b$ vaccine free of charge to close contacts of families with hepatitis b cases. http://www.ti.gov.cn/xw/bum/2 01904/t20190424_3653426.html. Accessed 24 April 2019.

24. Landry PF, Shen MM. Reaching migrants in survey research: the use of the global positioning system to reduce coverage bias in China. Polit Anal. 2005;13(1):1-22

25. Hu XJ, Xiao SW, Chen BL, Sa Z. Gaps in the 2010 measles SIA coverage among migrant children in Beijing: evidence from a parental survey. Vaccine. 2012;30(39):5721-5.

26. Hu FY, Niu L, Chen R, Ma Y, Qin X, Hu Z. The association between social capital and quality of life among type 2 diabetes patients in Anhui province, China: a cross-sectional study. BMC Public Health. 2015;15(1):786-92.

27. Firouzbakht M, Tirgar A, Oksanen T, Kawachi I, Tilaki HK, Nikpour M, et al. Workplace social capital and mental health: a cross-sectional study among Iranian workers. BMC Public Health. 2018;18(1):794-800.

28. Yi X. Professional features, AIDS knowledge and sexual risk perception: an empirical research from survey data on movement population. China Rural Survey. 2012;3:78-86.

29. Comrey A, Lee HA. First course in factor analysis. 2nd ed. New York: Psychology Press; 1992

30. Weinstein ND, Kwitel A, Mccaul KD, Magnan RE, Gerrard M, Gibbons FX. Risk perceptions: assessment and relationship to influenza vaccination. Health Psychol. 2007;26(2):146-51.

31. Ling M, Kothe EJ, Mullan BA. Predicting intention to receive a seasonal influenza vaccination using protection motivation theory. Soc Sci Med. 2019:233:87-92.

32. Prematunge C, Corace K, McCarthy A, Nair RC, Roth V, Suh KN, et al. Qualitative motivators and barriers to pandemic vs. seasonal influenza vaccination among health care workers: a content analysis. Vaccine. 2014; 32(52):7128-34.

33. Ernsting A, Lippke S, Schwarzer R, Schneider M. Who participates in seasonal influenza vaccination? Past behavior moderates the prediction of adherence. Adv Prev Med. 2011:1-6.

34. Webb TL, Sheeran P. Does changing behavioral intentions engender behavior change? A meta-analysis of the experimental evidence. Psychol Bull. 2006;132(2):249-68.

\section{Publisher's Note}

Springer Nature remains neutral with regard to jurisdictional claims in published maps and institutional affiliations.

Ready to submit your research? Choose BMC and benefit from:

- fast, convenient online submission

- thorough peer review by experienced researchers in your field

- rapid publication on acceptance

- support for research data, including large and complex data types

- gold Open Access which fosters wider collaboration and increased citations

- maximum visibility for your research: over $100 \mathrm{M}$ website views per year

At $\mathrm{BMC}$, research is always in progress.

Learn more biomedcentral.com/submissions 